\title{
LOS PRIMITIVOS DE SANTA CLARA DE ÚBEDA. APROXIMACIÓN FORMAL E ICONOGRÁFICA, FORTUNA CRÍTICA Y VICISITUDES DE UN PATRIMONIO DISPERSO ${ }^{1}$
}

\author{
Clara Beltrán Catalán \\ Universidad de Barcelona \\ clara@clarabeltran.com \\ José JoAQuín Quesada Quesada \\ Universidad de Jaén \\ josejqq@yahoo.es
}

\begin{abstract}
Abordamos el estudio estilístico e iconográfico de un conjunto de tablas de los siglos XV y XVI procedentes del Real Monasterio de Santa Clara de Úbeda y vendidas en la década de 1920 con la intervención del anticuario Celestino Dupont. Completamos este análisis con la fortuna crítica de estas piezas y sus vicisitudes posteriores una vez introducidas en el activo circuito del mercado de arte.

Palabras clave: orden franciscana; Úbeda; pintura valenciana; pintura andaluza; mercado de arte; coleccionismo; Gonçal Peris; Alonso de Villanueva; Celestino Dupont.
\end{abstract}

\section{THE PRIMITIVES OF SANTA CLARA OF UBEDA: STYLISTIC AND ICONOGRAPHIC STUDY, CRITICAL APPRAISALS AND VICISSITUDES OF A DISPERSED HERITAGE}

The authors study the stylistic and iconographic aspects of a collection of paintings on wood dating from the 15th and 16th centuries, originally in the Royal Monastery of Santa Clara at Úbeda. This collection was sold in the 1920s with the participation of the antique dealer Celestino Dupont. The research is complemented by an analysis of the critical appraisals given to these works and their history since their introduction into the art market.

Key words: Franciscan order; Úbeda; Valencian painting; Andalusian painting; art market; art collecting; Gonçal Peris; Alonso de Villanueva; Celestino Dupont.

El Real Monasterio de Santa Clara (fig. 1) supone un destacado hito del patrimonio históricoartístico de Úbeda, fundamental en la interpretación de su urbanismo en clave conventual, toda vez que las desamortizaciones decimonónicas y la hegemonía de la magnífica arquitectura palaciega renacentista de la ciudad diluyen con frecuencia esa percepción de la Úbeda histórica.

\footnotetext{
${ }^{1}$ Agradecemos los consejos de los profesores Judith Berg Sobré, Rafael Cómez Ramos y Miguel Ángel León Coloma y la colaboración del anticuario Artur Ramón y de la comunidad de Franciscanas Descalzas del Real Monasterio de Santa Clara de Úbeda.
} 


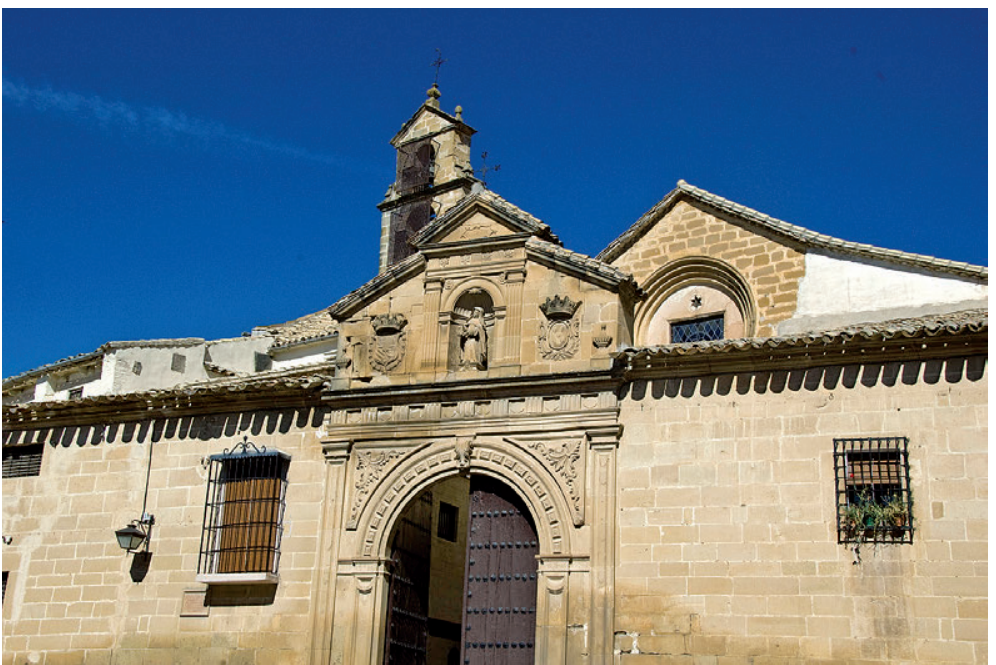

Fig. 1. Exterior del Real Monasterio de Santa Clara (Úbeda, Jaén). Fotografía de José Luís Latorre Bonachera.

La llegada de las monjas de Santa Clara debió producirse justo tras la reconquista castellana en 1234, junto a la de las otras órdenes que, patrocinadas por la Corona, contribuyeron a la cristianización de la ciudad. La primera constancia documental del monasterio de las clarisas se remonta a 1290, cuando don Rodrigo, obispo de Marruecos, le otorga una serie de indulgencias, aunque la tradición atribuye su fundación al propio conquistador de Úbeda, Fernando III el Santo. Su primera ubicación se localizaba extramuros, tal y como era habitual en los cenobios franciscanos. No obstante, la inseguridad de este emplazamiento, puesta de manifiesto en la "razzia" de 1369, motivó su traslado al lugar que hoy ocupa, autorizado en 1373. Según el cronista franciscano Laín y Roxas ${ }^{2}$, el emplazamiento definitivo del monasterio se llevó a cabo aprovechando unas casas confiscadas por la Corona a unos judíos, lo que determina el carácter sedimentario y orgánico del actual edificio, en el que funciones, formas y cronologías muy diversas conviven en los mismos espacios.

Privilegios pontificios, mercedes regias - una relación con la Corona que aparte de su hipotética fundación fernandina tiene su principal hito en la estancia de la reina Isabel la Católica en el cenobio en 1487, de camino a la campaña de Baza- y donaciones de particulares, han dotado de especial relevancia al monasterio, permitiéndole la conformación de un patrimonio artístico que, en el caso de los bienes muebles, ha sido severamente diezmado por los naufragios históricos, en especial la Guerra Civil ${ }^{3}$.

Pretendemos contribuir al conocimiento de este legado con el estudio de varias pinturas de los siglos XV y XVI procedentes del cenobio y vendidas en la década de 1920, en una serie de operaciones con la implicación, en mayor o menor medida, de un anticuario de origen francés afincado por aquel tiempo en Sevilla: Celestino Dupont Mathieu (1859-1940) ${ }^{4}$.

\footnotetext{
Laín y Roxas, 2012: 92.

${ }^{3}$ Las noticias más importantes sobre este monasterio ubetense las aportan Ruiz Prieto, 1906: 137-141 y Torres Navarrete, 1990: 215-233. Actualmente José Joaquín Quesada Quesada está llevando a cabo una investigación sobre este cenobio con el título El Real Monasterio de Santa Clara de Úbeda. Aproximación histórica y patrimonial, pendiente de publicación.

${ }^{4}$ Celestino Dupont se instaló en Barcelona en la década de los 80 del siglo XIX y pronto se convirtió en uno de los agentes más importantes del momento. Por sus manos pasaron infinidad de obras de arte, muchas de ellas de gran valor patrimonial, que hoy descansan en museos y colecciones particulares nacionales e internacionales. Para más información acerca de este anticuario véase: Beltrán Catalán, 2014. 2016 (en prensa).
} 


\section{Aproximación formal e iconográfica a las tablas}

Las piezas que nos ocupan son, por un lado, una Santa Lucía del primer cuarto del siglo XV, atribuida al pintor valenciano Gonçal Peris, y puesta en relación con una Anunciación cuya autoría se otorga al círculo de este $\operatorname{artista}^{5} \mathrm{y}$, por otro, un conjunto de cuatro tablas con escenas de la vida de la Virgen y una quinta representando a Santa Clara, realizadas por el pintor Alonso de Villanueva aproximadamente un siglo después. Pertenecieron al Real Monasterio de Santa Clara de Úbeda hasta la primera mitad de la década de 1920, momento en el que fueron vendidas con la intervención -en algunos casos confirmada, y en otros supuesta- de Celestino Dupont.

La Santa Lucía, hoy conservada en el Williams College Museum of Art de Williamstown (Massachusetts, EE.UU) (WCMA 54.2) (fig. 2), fue atribuida por Chandler R. Post en 1935 -entonces repintada e identificada como Santa Cecilia- al taller de Pere Nicolau y Marçal de Sax ${ }^{6}$.

La tradición narra que Santa Lucía no sólo evitó los tormentos a los que fue condenada antes de ser decapitada, sino que también escapó de la concupiscencia de sus verdugos ${ }^{7}$. Por tanto, su presencia en un monasterio femenino no podía ser más apropiada. Durante la Edad Media su culto conoció una especial difusión, tanto por su consideración de santa protectora de la vista, como por el traslado de sus reliquias desde Constantinopla a Venecia en la IV Cruzada (1204).

La mencionada alteración de su fisonomía para darle la apariencia de Santa Cecilia (fig. 3) se produjo, según Post, a finales del siglo XV por un artista del círculo del maestro de Artés ${ }^{8}$. El culto a esta mártir romana venerada como patrona de la música se intensificó a raíz del descubrimiento de sus reliquias en 1594, por lo que podría pensarse que la transformación de la pintura se dio en este momento. Sin embargo, el análisis de las dos capas de pigmento retiradas al ser restaurada en 1983 incluyen azul de Prusia, cuyo uso no se generalizó hasta mediados del siglo XVIII. Al respecto, los técnicos consultados retrasaron los repintes hasta el siglo XIX, aventurando que podrían haberse realizado con vistas a sacar la pieza al mercado artístico ${ }^{9}$.

Tras la restauración señalada la santa efigiada recuperó tanto su identidad como su apariencia originales. Fue a partir de este momento cuando la Santa Lucía pasó a considerarse obra del valenciano Gonçal Peris -o al menos de su órbita- y fue datada hacia 1420-1425, principalmente por las notables semejanzas que presenta con la Santa Bárbara del retablo de Puertomingalvo, obra atribuida a Peris, hoy en el Museu Nacional d'Art de Catalunya (MNAC/MAC 035672-CJT), hasta el punto de que ambas figuras parecen compartir el mismo cartón ${ }^{10}$.

Caracterizada con la palma del martirio y los ojos en el plato, la Santa Lucía se nos presenta como una figura plena de una elegancia subrayada por las armónicas líneas que describen sus rubios cabellos y sus ropajes, entre el naturalismo y la idealización. No faltan detalles a la suntuosidad de su indumentaria y aderezo, situándose sobre una lujosa alfombra brocada ante un trono de líneas góticas. A nivel formal, la pintura se inscribe con rotundidad en las coordenadas plásticas valencianas coetáneas, tanto en el dibujo como en la composición y en el manejo de los dorados. Técnicamente, la utilización de la italiana terraverde es también distintiva de la pintura gótica en Valencia.

\footnotetext{
${ }^{5}$ Berg Sobré/Travers Newton, 1998: 410.

${ }^{6}$ Post, 1935: 336.

${ }^{7}$ Reáu, 1996: 269.

${ }^{8}$ Berg /Travers, 1998: 408.

${ }^{9}$ Berg/Travers, 1998: 413.

${ }^{10}$ Berg/Travers, 1998: 408-409. El retablo de Santa Bárbara procede de la ermita homónima en Puertomingalvo (Teruel), e ingresó en el MNAC en 1950, aunque se hallaba depositada en el Museo desde 1934 procedente de la colección Bosch i Catarineu. Francesc Ruíz Quesada, que ha estudiado este retablo, apunta a una "industrialización" avant la lettre de modelos (Ruiz, 2012: 22-23). Por su parte, Rosa Alcoy lo considera una obra conjunta de los artistas Gonçal Peris y Jaume Mateu (Alcoy, 1992: 260-263).
} 


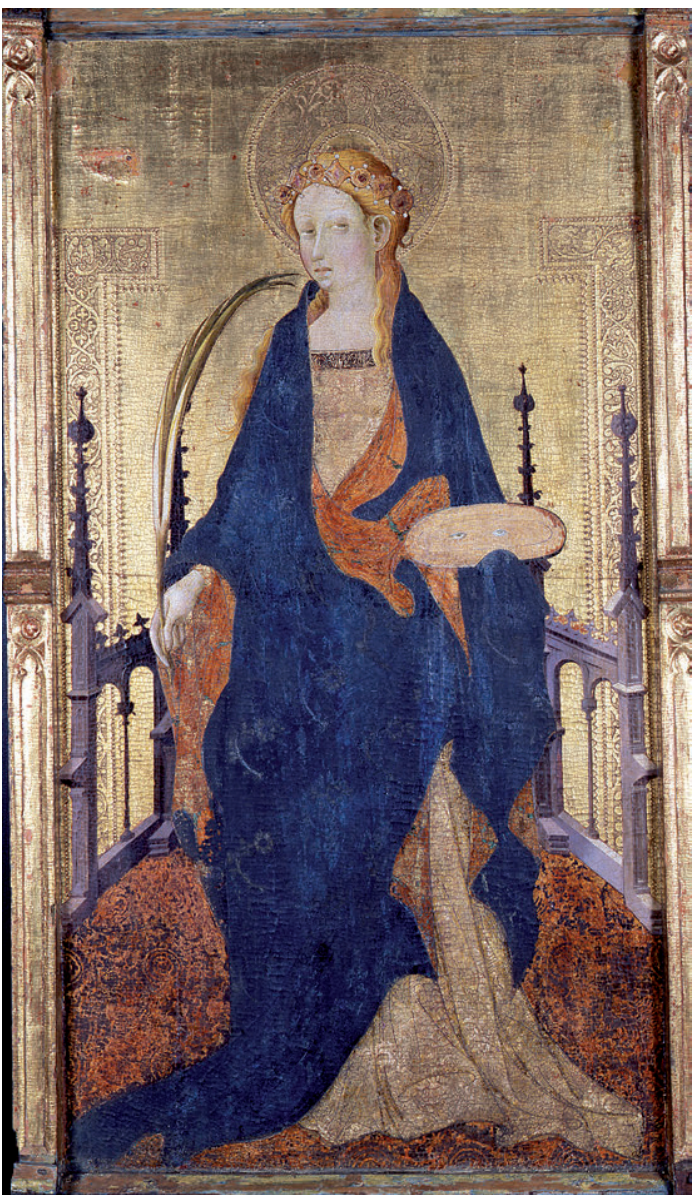

Fig. 2. Gonçal Peris, c. 1400-1450, Santa Lucía, Temple sobre tabla, 142,6 × $82,6 \times 9,8 \mathrm{~cm}$., Williams College Museum of Art, Willliamstown, MA.

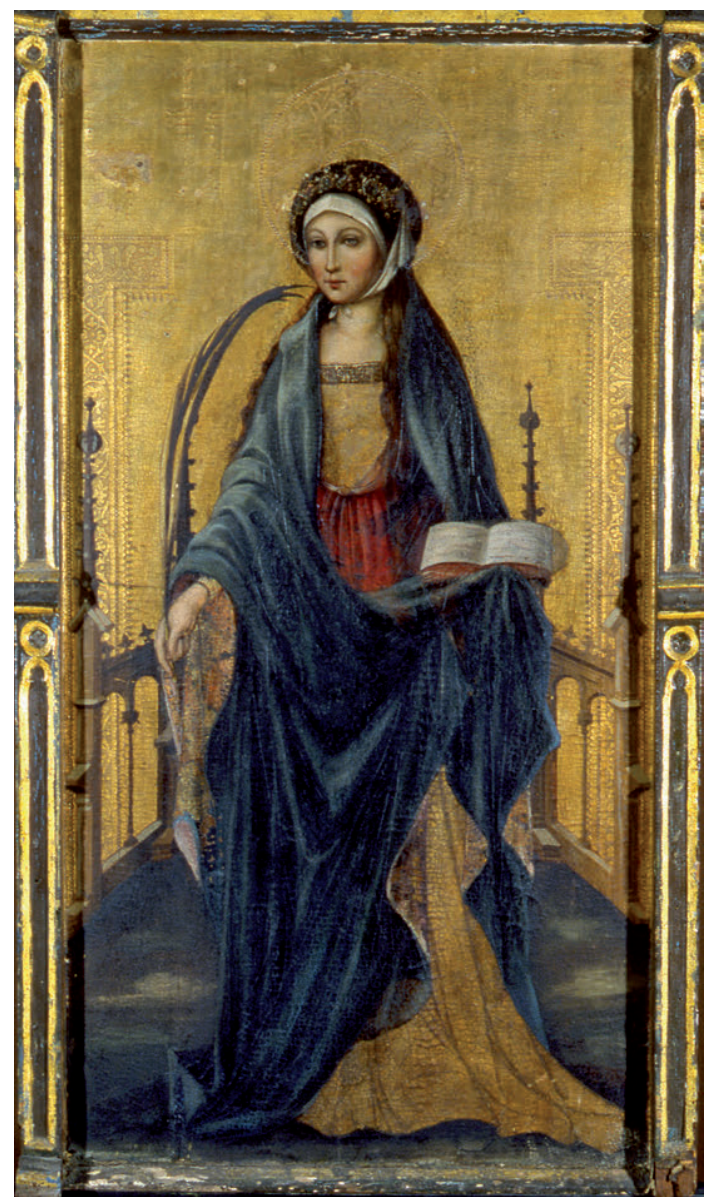

Fig. 3. Gonçal Peris, c. 1400-1450, Santa Lucía (con la iconografía de Santa Cecilia, antes de la restauración de 1983), Temple sobre tabla, 142,6 x 82,6 x 9,8 cm., Willliams College Museum of Art, Williamstown, MA.

Los indicios acerca de su procedencia nos los proporciona únicamente la factura de venta de la misma emitida por Celestino Dupont en 1924 (fig. 4), cuyo asunto es "1 tableau primitif provenant du convent de St. Clara de Úbeda XVIe/2500 [pesetas] C. Dupont [firma]" ". En principio, esta procedencia parece difícil de conciliar con la filiación valenciana debido a que para los encargos plásticos en el Alto Guadalquivir se solía acudir a talleres más cercanos que los levantinos ${ }^{12}$. Difícil,

${ }^{11}$ Conocimos la existencia de esta factura gracias al artículo de Berg y Travers, , 1998: 408. Por fortuna hemos podido localizarla siendo, además, una de las pocas emitidas por Celestino Dupont de las que tenemos constancia y que nos permite situarlo en Sevilla a principios de los años veinte, tras abandonar Barcelona.

${ }^{12}$ La ausencia de artistas plásticos es casi endémica durante el Medievo en la zona de la Loma de Úbeda, recurriéndose para obras de importancia a creadores foráneos. Pensemos en el retablo mayor de la desaparecida Colegiata de Santa María del Alcázar de Baeza, obra sevillana, del entorno de Francisco Sánchez (segunda mitad del siglo XV). 


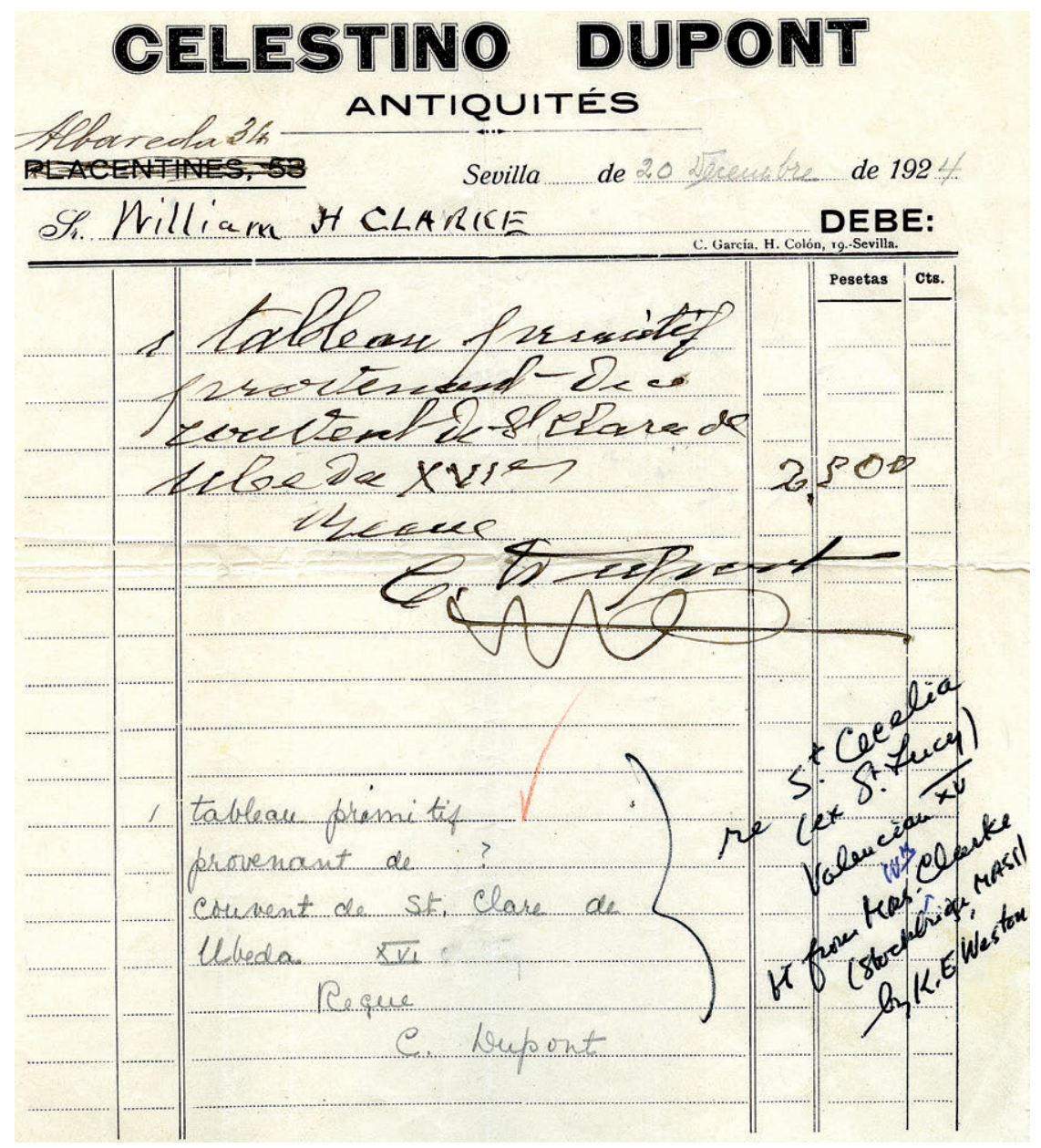

Fig. 4. Factura de compra de la tabla de Santa Lucía, 1924. Fuente:

Curatorial file, Williams College Museum of Art, Williamstown, MA.

pero no imposible; Berg recuerda como obras del propio Peris se localizan en El Burgo de Osma o que Borrassà atendió encargos en Burgos ${ }^{13}$.

La Santa Lucía ofrece, además, paralelismos formales y de tamaño con otra obra atribuida a Gonçal Peris ${ }^{14}$ y localizada en el Museu Nacional d'Art de Catalunya: una Anunciación que perteneció al coleccionista Lluís Plandiura, ${ }^{15}$ quien afirmaba que su procedencia era Úbeda ${ }^{16}$ (MNAC/MAC 04511) (fig. 5).

${ }_{13}^{13}$ Berg/Travers, 1998: 408.

${ }^{14}$ La obra ha pasado por otras atribuciones: Maestro de Guimerá según Post (Pareja/ Megía, 1990: 405); círculo de Marçal de Sax para Gudiol (Gudiol, 1955: 198). En el catálogo del MNAC aparece asignada a un artista anónimo valenciano. Véase: <http://www.museunacional.cat/es/colleccio/anunciacion/anonim-valencia/004511-000>.

${ }^{15}$ Plandiura fue un ávido coleccionista de arte medieval, de quien sabemos que realizó tratos comerciales puntuales con Celestino Dupont. En 1932 su exquisita colección pasó a integrarse en los fondos del Museo Nacional d'Art de Catalunya. Véase: Berenguer, 2010: 11-25; 2002: 23-40.

${ }_{16}$ Procedencia que, a pesar de ser considerada dudosa, es aceptada por la historiografía del arte en Andalucía. Véase: Pareja/ Megía, 1990: 407. 


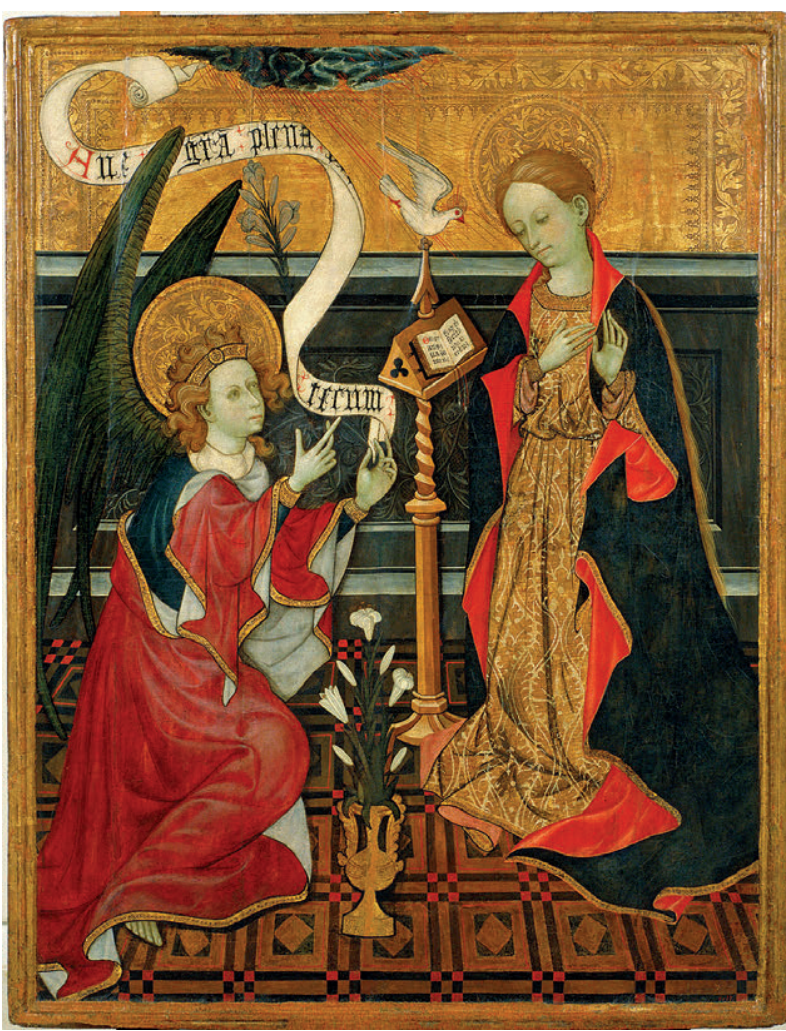

Fig. 5. Círculo de Gonçal Peris, Anunciación, c. 1410-1430, temple sobre tabla, $115,5 \times 94 \mathrm{~cm}$, (C) Museu Nacional d'Art de Catalunya, Barcelona. Foto: Jordi Calueras.
Tratamiento de ropajes, delineado de rostros, manos y cabellos, delicadeza en el dibujo y la composición, y fondos dorados son similares en ambas tablas, lo que permitió a Berg formular la hipótesis de que podrían haber formado parte de un mismo retablo pese a existir una diferencia de seis centímetros entre ellas, teniendo en cuenta que la Anunciación carece del marco original y la Santa Lucía sí lo conserva ${ }^{17}$. La existencia de dos obras cronológica y estilísticamente tan próximas y a las que se atribuye la misma procedencia avalan que, efectivamente, el origen podría ser el mismo, aún cuando a priori los datos que asignaran la existencia de estas obras medievales valencianas en Úbeda pudieran parecer poco creíbles o fruto de un error ${ }^{18}$. No es descabellado pensar, por tanto, que integrarán un mismo retablo situado en el monasterio de Santa Clara o bien en otro templo, como el desamortizado convento de San Francisco, donde existía una capilla dedicada a Nuestra Señora de la Encarnación.

Además, la existencia de tratos comerciales entre Plandiura y Dupont a comienzos de los años veinte ${ }^{19}$ hace plausible la hipótesis de que quizás fue éste quien le vendió la pieza al coleccionista, pese a carecer en este caso de constancia documental.

Mucho menos dudoso y mejor documentado es el origen ubetense del conjunto de cinco tablas realizadas por Alonso de Villanueva - activo en la primera mitad del siglo XVI- que salieron de Santa Clara en 1922 para pasar -con la probable intermediación de Dupont, que adquirió con seguridad una de ellas- a la colección de Carlos Pickman en Sevilla ${ }^{20}$.

${ }^{17}$ Berg/Travers, 1998: 407, 410, 411. Berg sugiere que el compartimento de la Anunciación podría ser la tabla central, y que la Santa Lucía se situaría sobre ella.

${ }^{18}$ Por ejemplo, Gudiol cuestionaba en su día la procedencia de la tabla. Véase: Gudiol, 1955: 198.

19 En el fondo personal de Lluís Plandiura se hallan algunas facturas que datan de 1921 (AHCB, Fondo personal de Lluís Plandiura i Pou 5D.54-9/ LP45-170-171) así como una carta enviada por Dupont del mismo año en la que se dirige al coleccionista de una forma bastante afectuosa, lo que prueba que tendrían una cierta amistad (AHCB, Fondo personal de Lluís Plandiura i Pou 5D.54-7/LP36-103).

${ }^{20}$ Probablemente se trata de Carlos Pickman Pérez (1888-1971), marqués de Pickman y gran amante de las artes. Descendiente de Charles Pickman Jones (1808-1883) -comerciante inglés que se instaló en Sevilla y adquirió el desamortizado monasterio de la Cartuja para instalar su fábrica de cerámica, la célebre "La Cartuja de Sevilla"-, a su fallecimiento dejó una valiosa colección de antigüedades en su casa-palacio ("Necrológicas. El marqués de Pickman". En: $A B C$ Sevilla, 2/IX/1971: 40). Las tablas no fueron la única adquisición de Pickman en Úbeda ni la más importante y des-

Archivo Español de Arte, vol. LXXXIX, n. ${ }^{\circ}$ 356, pp. 341-357, octubre-diciembre 2016 ISSN: 0004-0428, eISSN: 1988-8511, doi: 10.3989/aearte.2016.23 
Representan la Anunciación (fig. 6), la Natividad (fig. 7), la Epifanía (fig. 8), el Llanto sobre Cristo Muerto (fig. 9) y una Santa Clara (fig. 10), y Gómez Moreno señalaba la posibilidad de que pertenecieran al primitivo retablo mayor de la iglesia del monasterio de las clarisas $^{21}$. En efecto, se avienen bien por su cronología con la construcción de la actual capilla mayor en el primer cuarto del siglo XVI. Su iconografía mariana también apoya esta hipótesis, estando en sintonía con la Coronación de la Virgen representada en la pintura mural del primitivo presbiterio ${ }^{22}$. A partir del siglo XIII, el culto y la iconografía de la Madre de Dios conocen un gran desarrollo, en parte promovido por las ordenes mendicantes, "verdaderos caballeros de la Virgen"23, con hitos devocionales como el Speculum beatae Mariae atribuido a San Buenaventura. La espiritualidad bajomedieval asigna a la Virgen María el papel de intermediaria siempre favorable hacia la humanidad sufriente, asumiendo plenamente el elemento humano tan característico de la espiritualidad franciscana. La hipótesis de que formaran parte del retablo mayor cuenta, además, a su favor, con su tamaño; $92 \mathrm{~cm}$. aproximados de ancho muy compatibles con la luz $-336 \mathrm{~cm} .-$ del arco conopial de la capilla mayor que alojaría este retablo (fig. 11). De estar en lo cierto, estas dimensiones nos hacen pensar en una estructura de retablo de tres calles con elementos de arquitectura lígnea enmarcando las pinturas.

Este conjunto probablemente estuvo integrado por más piezas, pues a ellas parece referirse el testimonio de una monja que relata que en la Guerra Civil "Cuadros de mucho mérito los quemaron en el patio. Estos cuadros eran tablas, las que representaban varios misterios, en pintura y oro repujado"24. Técnica, iconografía mariana y uso del dorado coinciden con las pinturas que nos ocupan, además de que el considerarlas "de mucho mérito" está en consonancia con el hecho de que pocos años antes otras tablas similares hubieran sido vendidas a Pickman y Dupont.

El autor, Alonso de Villanueva, trabaja en Córdoba entre 1510 y la década de 1540 y, por tanto, está en conexión con el grupo de artistas que -con Pedro Romana a la cabeza tras la marcha de Alejo Fernández a Sevilla en 1508- abastecen la demanda de pintura en la zona, llegando su producción hasta el reino de Jaén ${ }^{25}$. Precisamente los caracteres formales que se asignan a Romana -limitación expresiva, composiciones equilibradas y fondos de arquitecturas "al romano"- se adecúan al estilo de Villanueva, aunque con un peso mayor de la tradición flamenca. Lo dilatado de su producción, que llega al ecuador de la centuria, permite pensar que su estética tomó con posterioridad una deriva plenamente renacentista. Villanueva estuvo en Úbeda en varias ocasiones, atendiendo los encargos pictóricos de una ciudad que, a pesar de su intensa producción arquitectónica, carece de una actividad similar en la pintura y tiene que recurrir a pintores foráneos a lo largo del siglo XVI. En 1545 realiza dos retablos, uno para la capilla de Rodrigo Ortega en la desaparecida parroquia de Santo Tomás, y otro para el doctor Villareal. Por las mismas fechas está documentada su participación en el de la parroquia de Porcuna (Jaén). Sin embargo, sólo se conserva una obra suya en Úbeda: la tabla de Nuestra Señora de los Remedios que procedente de la derruida Puerta de Toledo se localiza hoy en el Ayuntamiento. Si atendemos a la tradición que señala que ante esta pintura juró Carlos I guardar los fueros y privilegios de Úbeda en 1526, sería

\footnotetext{
tacada: en la década de 1920 compró la portada de la casa de los Aranda, originariamente en la calle Compañía, y la trasladó a su residencia sevillana de la calle Lope de Rueda, en pleno barrio de Santa Cruz.

${ }^{21}$ Gómez Moreno, 1921: 67.

${ }^{22}$ Cuando a principios del siglo XVI la familia Salido construyó su capilla funeraria, ésta se convirtió en nuevo presbiterio, cambiando la primitiva orientación de la iglesia. El presbiterio original fue tabicado y aislado del resto de la iglesia, convirtiéndose en cementerio de la comunidad. El mural de la Coronación de la Virgen, muy maltratado y con grandes lagunas existe aún y es una interesante muestra de pintura bajomedieval.

${ }^{23}$ Mâle, 2001: 264.

${ }^{24}$ Tarifa/Linage, 1994: 1083.

${ }^{25}$ Véase Angulo, 1944: 227-236; 1954: 147. Moreno, 2002: 83-109.
} 


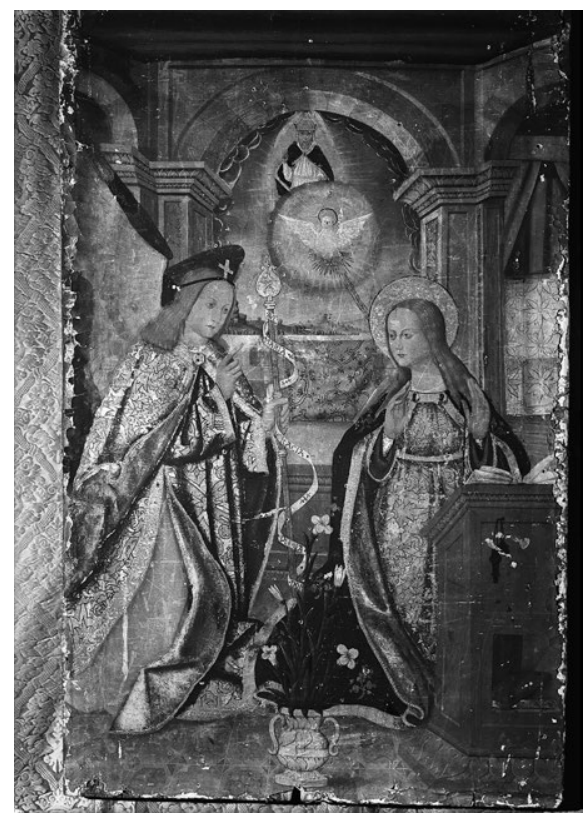

Fig. 6. Alonso de Villanueva, Anunciación, siglo XV, temple sobre tabla con oro bruñido, Colección

Moragas (Barcelona). (C) Fundació Instituto Amatller de Arte Hispánico. Archivo Mas.

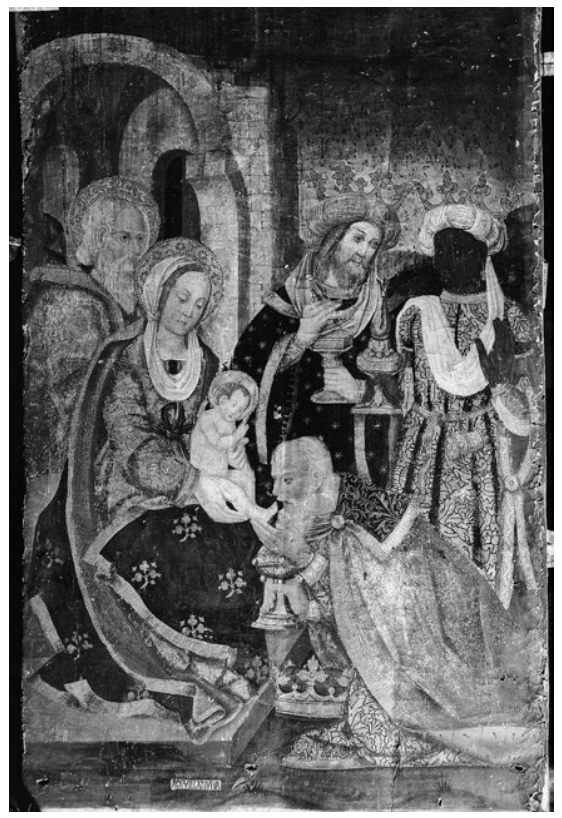

Fig. 8. Alonso de Villanueva, Epifanía, siglo XV, temple sobre tabla con oro bruñido, $1,98 \times 0,91 \mathrm{~m}$, ubicación desconocida. (C) Fundació Instituto Amatller de Arte Hispánico. Archivo Mas.

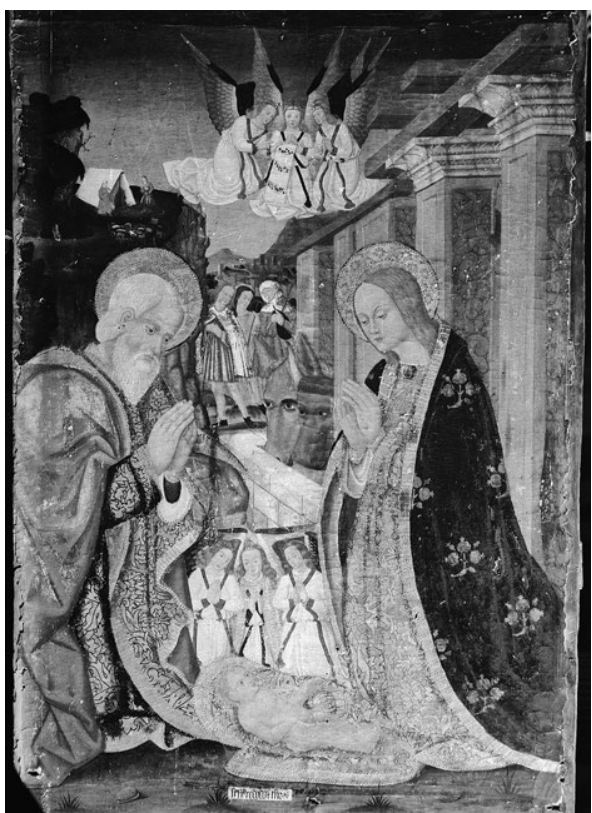

Fig. 7. Alonso de Villanueva, Natividad, siglo XV, temple sobre tabla con oro bruñido, 1,67 x 0,92 m, Colección Pickman (Sevilla). (C) Fundació Instituto Amatller de Arte Hispánico. Archivo Mas.

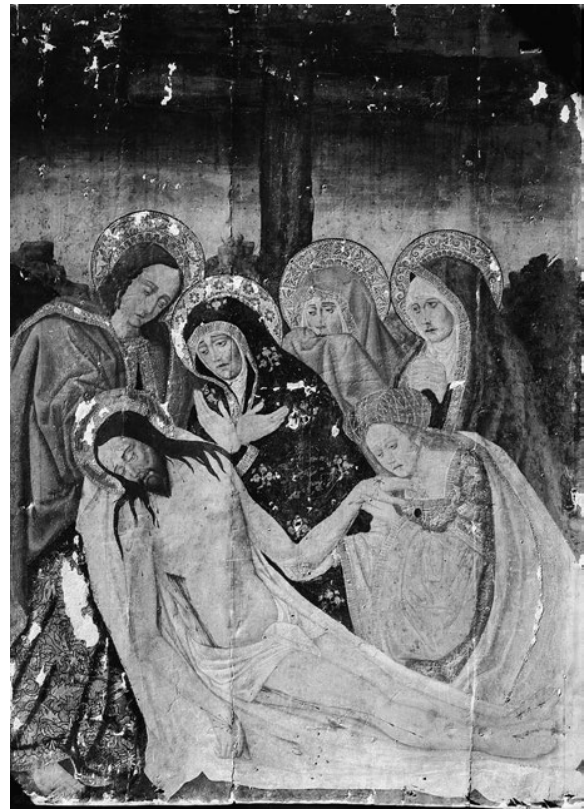

Fig. 9. Alonso de Villanueva, Lamentación sobre Cristo muerto, siglo XV, temple sobre tabla con oro bruñido, 1,58 x 1,14 m, Colección Pickman (Sevilla). (C) Fundació Instituto Amatller de Arte Hispánico. Archivo Mas. 


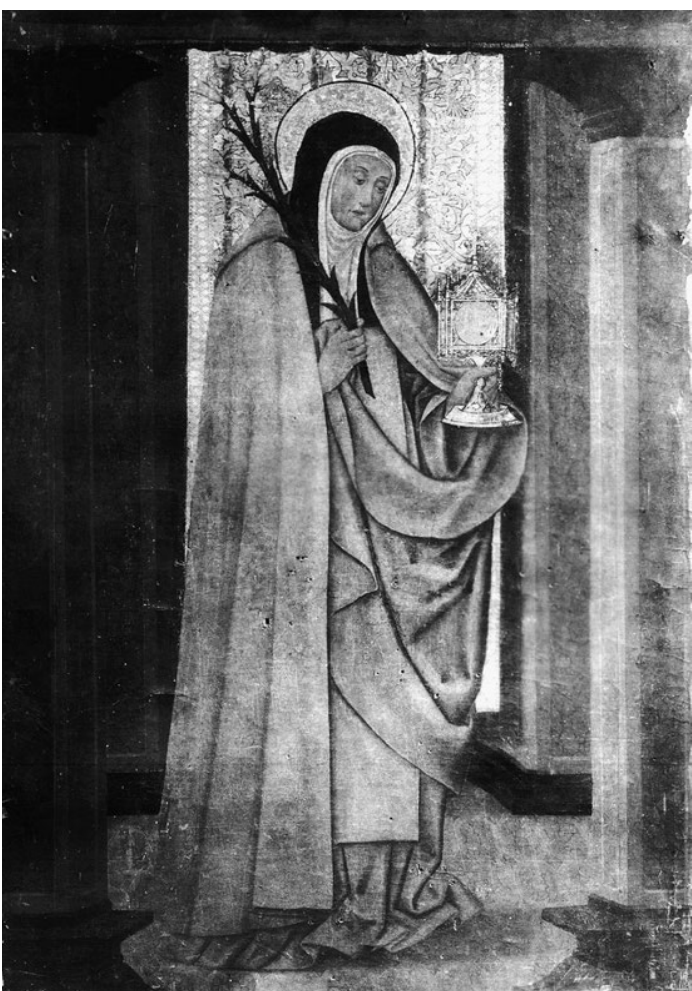

Fig. 10. Alonso de Villanueva, Santa Clara, siglo $\mathrm{XV}$, temple sobre tabla con oro bruñido, $1,57 \times 0,95$ m., Colección Pickman (Sevilla). (C) Fototeca Laboratorio de Arte de la Universidad de Sevilla.

forzosamente anterior a esa fecha y por tanto más cercana a las tablas que nos ocupan. En cualquier caso, en 1559 el artista la aderezó y refrescó por encargo del concejo ${ }^{26}$.

Técnicamente, las pinturas que nos ocupan están realizadas al temple de huevo sobre tabla de pino, "con oro bruñido y grabado en nimbos, brocados, forrajas, orfebrería, etcétera" ${ }^{27}$. Presentan un carácter híbrido, de transición entre el mundo flamenco y las nuevas formas italianizantes, propio del primer Renacimiento hispánico. La deuda con la plástica neerlandesa determina el tratamiento de los personajes, especialmente los ángeles; de las telas -minuciosamente descritas con brocados y dorados- y de la perspectiva, con tentativas de crear un espacio creíble no siempre afortunadas; pero precisamente en los fondos arquitectónicos "all'antica" se advierte ya la estética renacentista.

El ejemplo más significativo de este sincretismo lo encontramos en la Anunciación. Vestiduras y tejidos revelan un deleite en la representación de oros y brocados plenamente goticista - con granadas recamadas en el manto de la Virgen, evocadoras de la reciente conquista de Granada-, combinado con un anecdotismo de sabor flamenco que se detiene en describir el mobiliario de la casa de María. Sin embargo, el tratamiento del espacio está en conexión con el Renacimiento: una estancia tridimensional, abierta al paisaje en sintonía con las propuestas cuatrocentistas, concebida con elementos arquitectónicos y mobiliario clasicistas. La figura del arcángel suscribe plenamente los mencionados modelos flamencos. Arrodillado frente a la Virgen, la elocuencia de su mensaje queda subrayada por su gesto de "adlocutio" y la filacteria con el texto AVE MARIA GRACIA PLENA DOM del cetro. La Virgen interrumpe su lectura -el profético Ecce Virgo concipiet de Isaías según la Patrísticacon un gesto de sorpresa que delatan mejor sus manos que su inexpresivo rostro. El planteamiento de la escena sigue con fidelidad el tratamiento iconográfico del tema en el Medievo occidental, en el que se ha visto la influencia de las Meditationes del Pseudo Buenaventura. En ellas se describe que la Virgen, al recibir el saludo angélico, detuvo su lectura, "dobló las rodillas y juntó las manos diciendo He aqui la esclava del Señor", y de igual forma al mismo texto se atribuye el motivo del arcángel genuflexo. No obstante, la Virgen arrodillada aparece ya en los frescos de Giotto de la capilla Scrovegni de Padua, anterior a la difusión del Pseudo Buenaventura; y la posición de San Gabriel se conecta también con "los usos de la vida cortesana, en las costumbres feudales de los caballeros y de los trovadores que doblaban la rodilla ante su dama"28. Sea o no una aportación

\footnotetext{
${ }^{26}$ Moreno Mendoza, 2002: 85-86

27 Gómez Moreno, 1921: 68.

${ }^{28}$ Réau, 1996: 190.
} 


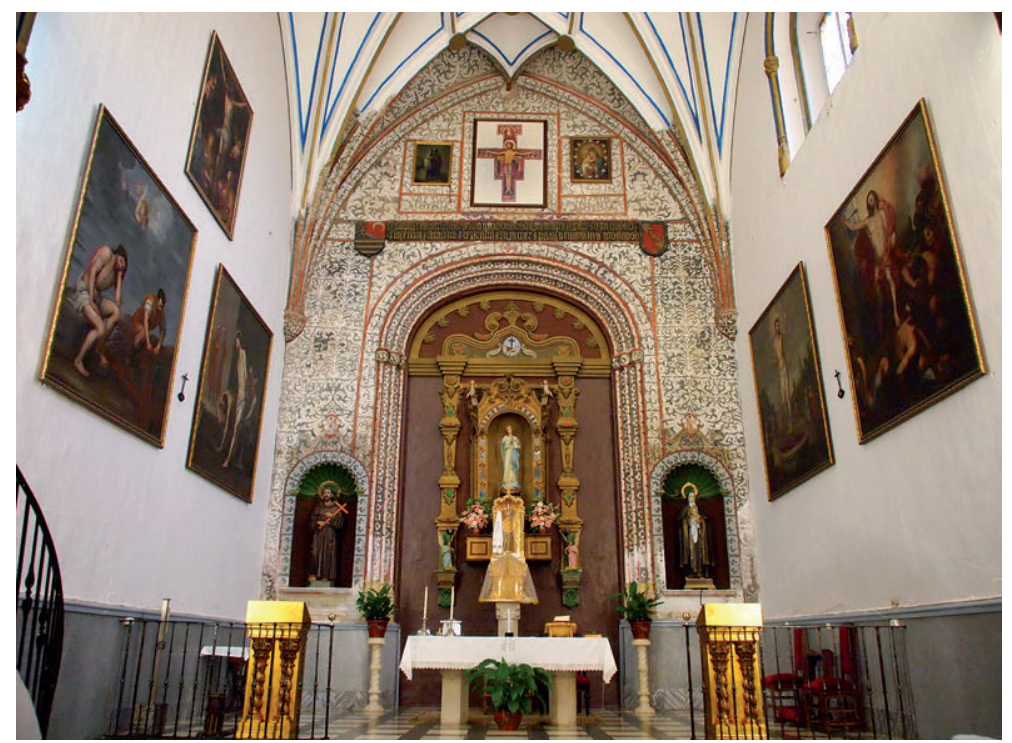

Fig. 11. Capilla Mayor del Real Monasterio de Santa Clara (Úbeda, Jaén). Fotografía: José Joaquín Quesada Quesada, 2012.

original del Pseudo Buenaventura, no podemos olvidar la importancia de sus Meditationes en la difusión y consolidación de pautas iconográficas.

La Natividad se adscribe también a la tradición iconográfica, con la Virgen y San José de rodillas y orantes ante el Niño, posición influenciada por las Revelaciones de Santa Brígida y el contagio iconográfico de las adoraciones de los pastores y los Magos en las que éstos aparecen genuflexos ${ }^{29}$. Los ángeles remiten de nuevo a la pintura flamenca, vistiendo "amplias albas, estolas cruzadas sobre el pecho, diademas con cruces sobre la blonda cabellera y capa coral uno de ellos" ${ }^{\prime 30}$. Además de pautar la profundidad espacial, las pilastras de la maltrecha arquitectura del portal revelan la fascinación por las ruinas de la antigua Roma, siendo un elemento que Brigstocke $^{31}$ relaciona con el templo romano de la Paz que, según la Leyenda dorada de Jacopo della Voragine, se derruyó misteriosamente la noche de la Natividad, simbolizando el tránsito de una etapa caduca a una nueva era. El paisaje del fondo sirve de escenario a las tiendas de campaña de los pastores, que se acercan avisados por los ángeles hacia el pesebre de Belén; suscriben la tradición iconográfica formulada en la Edad Media, manifestando el recuerdo de las pastorales y autos de Navidad en sus instrumentos musicales ${ }^{32}$.

Esta tabla y la anterior presentan unas importantes analogías compositivas con otras pinturas de similar temática, de finales del siglo XV, pertenecientes al Monasterio de Santa Clara de Moguer (Huelva) ${ }^{33}$, lo que nos permite hablar del manejo de una estampa común bastante difundida, con seguridad centroeuropea.

La composición de La Epifanía parte, con variantes, de una estampa de Schongauer, también utilizada en sus tablas homónimas por Alejo Fernández (Catedral de Sevilla, 1508-1512) y por Pedro Romana (San Bartolomé de Espejo, Córdoba, hacia 1504). La Virgen adquiere un intenso sabor

\footnotetext{
${ }^{29}$ Réau, 1996: 236-237.

${ }^{30}$ Gómez Moreno, 1921: 68 .

${ }^{31}$ Mencionado en Borobia, 2011: 159.

32 Réau, 1996: 244.

${ }^{33}$ Sobre estas pinturas, Pareja / Megía, 1990: 434-438.
} 
clásico en el velo que enmarca su rostro, mientras que las copas y recipientes de las ofrendas de los Magos y sus coronas toman como referencia las piezas de orfebrería coetáneas. El beso de Melchor a los pies del Infante procede del Pseudo Buenaventura, de donde pasó a Giotto y los Pisano ${ }^{34}$.

La Lamentación sobre Cristo muerto es un tema predilecto de la mística y la religiosidad popular. Se origina en el arte bizantino, pasando posteriormente a la plástica del Trecento y al centro de Europa. Los textos de Pseudo Buenaventura, Santa Brígida y Enrique Suso ${ }^{35}$ describen con emoción el dolor de la Virgen y el de sus acompañantes, entre ellos la Magdalena, que besa tiernamente las llagas del Redentor, aquí caracterizada por la mundanidad de su indumentaria, "brocada túnica, de escote cuadrado y manga corta, asomando debajo otra amplísima blanca, según moda flamenca; su manto es blanco, también, salpicado de flores de oro, y recógese la cabellera bajo una cofia, como turbante, labrada con oro formando red ${ }^{\prime 36}$. María asume un rol central en la composición; su dolor venía siendo objeto de reflexión devota y artística, gracias en gran medida a la espiritualidad franciscana, -recuérdense el Stabat Mater de Jacopone de Todi y las Vesperbild de los monasterios mendicantes centroeuropeos-. Los dolientes forman un grupo compacto que anula en este caso las referencias espaciales.

La última de las tablas representa a Santa Clara. Su elegante figura, para la que Gómez Moreno reclama mayor calidad que para el resto de las pinturas, se recorta sobre "una cortina de brocado, entre pilastras rojizas jaspeadas y con adornos romanos" $" 37$. Fundadora de las Clarisas y titular del monasterio, Santa Clara de Asís (1193-1243) se define iconográficamente por la custodia, alusiva al cerco de los sarracenos sobre San Damiano. Se cuenta que la santa tomó en sus manos el Santísimo Sacramento y pidió ser llevada a los muros del cenobio, poniendo en fuga a los asaltantes. Este episodio hagiográfico consagró a Santa Clara durante el Medievo como "defensor civitatis" y probablemente contribuyó a la extensión de su iconografía, en relación con la amenaza turca en el Mediterráneo orienta ${ }^{38}$. Además del mencionado ostensorio -anacrónico, pues en tiempos de Santa Clara la Eucaristía se custodiaba en píxides- la santa sostiene un ramo de azucenas, atributo de pureza incorporado a su iconografía por los artistas medievales de Siena y Umbría ${ }^{39}$. Gómez Moreno aventura la posibilidad de que hiciera pareja con un San Francisco ${ }^{40}$.

\section{Fortuna crítica y vicisitudes posteriores de las obras}

La completa renovación experimentada a mediados del siglo XVIII por la iglesia de Santa Clara debió relegar a la clausura las tablas de Villanueva, hipotéticas integrantes del retablo mayor del templo. Ni Miguel Ruiz Prieto en su Historia de Úbeda (1906) ni Enrique Romero de Torres en su Catálogo de los monumentos históricos y artísticos de la provincia de Jaén (1913) las mencionan. Las dificultades económicas del monasterio a comienzos del siglo XX debieron empujar a las monjas a solicitar la autorización del obispado de Jaén para vender cuatro de estas pinturas, localizadas en un corredor junto al claustro Gómez Moreno, 1921, 67: Natividad, Epifanía, Lamentación sobre Cristo muerto y Santa Clara -nada se menciona de la Anunciación-.

La enajenación fue aprobada el 30 de septiembre de 1921 (fig. 12). Previamente el Delegado Regio de Bellas Artes en Jaén, el ubetense Alfredo Cazabán, seguramente a instancias del prelado,

\footnotetext{
34 Thode, 1993: 364.

35 Reau, 1996: 112.

36 Gómez Moreno, 1921: 68.

37 Gómez Moreno, 1921: 69.

38 Chavero, 1994: 36-37.

39 Reáu, 1996: 310.

40 Gómez Moreno, 1921: 69.
} 


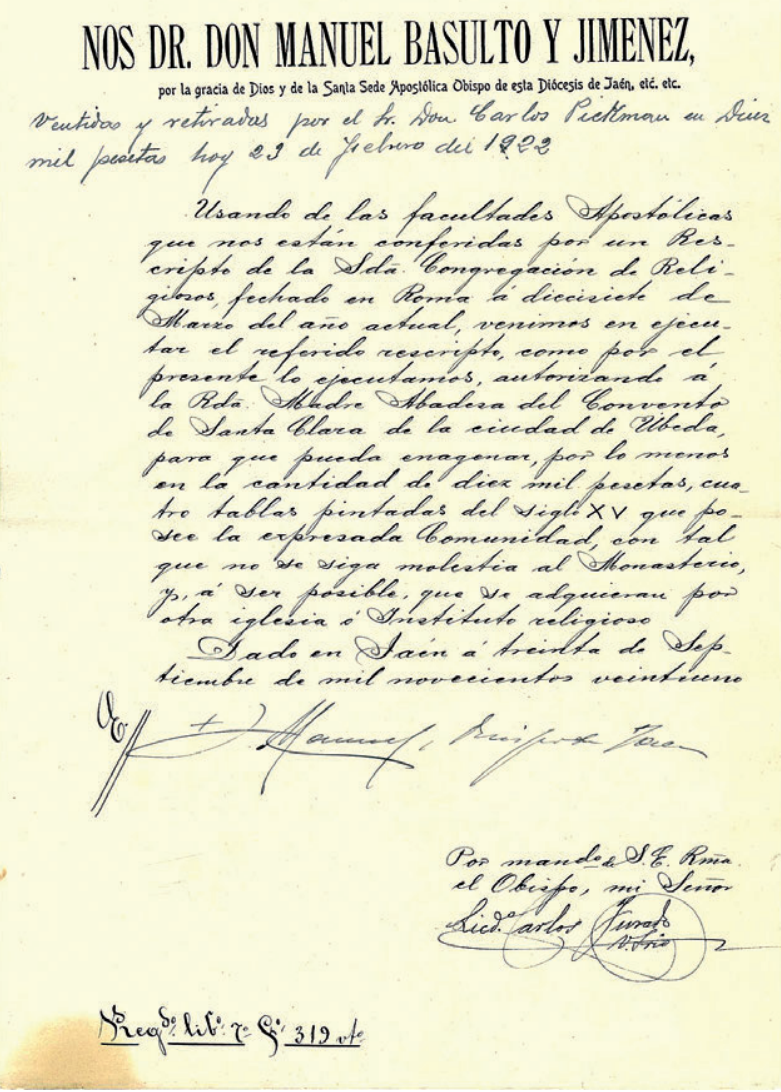

Fig. 12. Documento que autoriza la enajenación de cuatro tablas del siglo XV procedentes de Santa Clara de Úbeda (1921). Fuente: Archivo del Real Monasterio de Santa Clara (Úbeda, Jaén). solicitó al prestigioso historiador del arte Manuel Gómez Moreno un estudio de las mismas, publicado en marzo de 1921 en la revista Don Lope de Sosa ${ }^{41}$-dirigida por el propio Cazabán-, en el que se ofrecía en primer término las tablas al Estado. El juicio de Gómez Moreno acerca de su calidad no fue nada entusiasta, lo que facilitaría la aprobación definitiva de su venta. Las describió como:

obras muy arcaizantes en cuanto a su técnica de temple y con oro (...) su arte está calcado sobre los patrones flamencos más vulgares (...) sin genialidad alguna y pobremente interpretados, revelando el encogimiento que la gravedad hierática imponía a nuestros artistas, pero ya en lo accesorio dase entrada a temas nuevos italianos de lo más embrionario: así las arquitecturas (...) el estudio directo del natural está siempre muy ausente; es cosa de receta y de segunda o tercera mano todo, muy por bajo de la mayoría de obras coetáneas, que dan la nota media de nuestro desarrollo y potencialidad pictórica en aquel periodo ${ }^{42}$.

La presencia de dos nombres, el descifrado como Fray Fernando Redondo ${ }^{43}$ y el de Alonso de Villanueva le hizo pensar al estudioso en dos artistas diferentes, aún cuando "a no mediar tan elocuente prueba como las firmas, nadie pensaría sino que todas cuatro tablas eran obra de un sólo artífice (...) desde

luego la comunidad de ambiente, como emanación de un sólo taller, hermana estas obras" ${ }^{\text {"44 }}$. A pesar de la poco entusiasta valoración por parte de Gómez Moreno, Cazabán continuó intentando, sin éxito, la compra de las tablas por parte del Estado, tal y como se hace patente en el número de Don Lope de Sosa correspondiente a mayo de $1921^{45}$.

En el permiso expedido a la abadesa de Santa Clara se especificaba la necesidad de vender las piezas "por lo menos en la cantidad de diez mil pesetas (...) y a ser posible, que se adquieran por otra iglesia o Instituto religioso". Sin embargo, finalmente eran "vendidas y retiradas por el Sr.

${ }^{41}$ Estudio del que hemos ido reproduciendo algunas apreciaciones en nuestro análisis.

${ }^{42}$ Gómez Moreno, 1921: 69-70.

${ }^{43}$ En la inscripción de la tabla de la Natividad se leía en caracteres góticos "fr fer redodomr", que Gómez Moreno descifró como "Fray Fernando redondo magister" (Gómez Moreno, 1921:70).

${ }^{44}$ Gómez Moreno, 1921: 70-71.

45 Anónimo, 1921: 130. 
Don Carlos Pickman en Diez mil pesetas hoy 23 de febrero del 1922”, según reza en anotación añadida a posteriori al documento de enajenación ${ }^{46}$.

Siendo ya propiedad de Carlos Pickman, formaron parte de la muestra de Arte Antiguo celebrada con motivo de la Exposición Iberoamericana de 1929 en Sevilla ${ }^{47}$ A este momento deben pertenecer las reproducciones fotográficas de las mismas existentes en los fondos del Laboratorio de Arte de la Universidad de Sevilla, encargado de fotografiar las piezas exhibidas ${ }^{48}$.

En el catálogo ${ }^{49}$ de la exposición, la Epifanía, en virtud a su inscripción, se asigna a Alonso de Villanueva, entonces considerado erróneamente artista de la escuela valenciana del siglo XV. La Natividad, cuya inscripción se interpreta como "F. Rbo redbo m.z." se sustrae a la producción de Villanueva pero no a la escuela valenciana del siglo XV; a la Santa Clara se le da una cronología más avanzada, entre los siglos XV y XVI, sin atribución de escuela o autoría, y lo mismo ocurre con la Lamentación sobre Cristo muerto (identificada como Jesús descendido de la cruz), también sin autoría y fechada en el siglo XV. La adscripción a la escuela valenciana debe tener su origen en la experiencia de Dupont, que del mismo monasterio había sacado la Santa Lucía de Williamstown y, presumiblemente, la Anunciación de Plandiura, indudablemente levantinas; para justificarla, desconociendo la existencia de ningún Alonso de Villanueva, se menciona a Sancho Villanueva, pintor documentado en Valencia en 1398. En ningún caso se señala la procedencia ubetense de las piezas.

Las últimas noticias con las que contamos de las cuatro piezas datan de 1940, cuando Diego Angulo las vio en las colecciones de Pickman y Sánchez-Dalp ${ }^{50}$ y las incluyó en el tomo correspondiente a la pintura de comienzos del XVI de Ars Hispaniae, cuya redacción corría a su cargo, señalando que son las primeras obras en las que:

[...] el Renacimiento se manifiesta decididamente, al menos en los fondos arquitectónicos [...]. De pobre calidad artística y de estilo muy uniforme, representan historias de la vida de Jesús y una Santa Clara. Su autor es Alonso de Villanueva, que firma la Adoración de los Reyes. Tanto su estilo, que parece reflejar el del círculo de Pedro Romana, como su nombre permiten presumir su origen cordobés. Si el letrero del Nacimiento, "fra(y) fr(anciscus)redo(n)dom(agiste)r", es firma y no el apellido del franciscano que encargó la obra, que es lo más probable, su estilo sería el mismo que el de Villanueva. De Alonso de Villanueva consta la presencia en Córdoba en 1510 $\mathrm{y}$ en $1542-1546^{51}$.

${ }^{46}$ Archivo del Real Monasterio de Santa Clara de Úbeda.

47 Exhibidas en la sala 11 [núms. 33, 34, 35,36] del Palacio de las Bellas Artes (Anónimo, 1929:157-158), las obras compartían espacio con selectas pinturas sobre tabla del Gótico y el Renacimiento, entre las que destacaba la famosa Virgen de Tobed, que se atribuía a Pere Serra y actualmente a su hermano Jaume (Navarrete, 2014: 82). No fueron, las únicas piezas prestadas por Pickman. Entre otras, también se pueden mencionar, expuestas en esa misma sala, El milagro de san Ermengol, atribuido a la escuela catalana [núm. 37] o El nacimiento del niño Jesús, de Pedro de Córdoba [núm. 38] (Navarrete Prieto, 2014: 114, 152, 260, 308). Además de Carlos Pickman, fueron numerosos los prestadores particulares que concurrieron a la muestra, como la Viuda de Gestoso, el Marqués de Saltillo, la Duquesa Viuda de Osuna, el Marqués de la Reunión o Fernando López Cepero (Navarrete, 2014: 80).

${ }^{48}$ Esta labor fotográfica tiene el impagable mérito de permitirnos conocer las obras exhibidas en tan magna exposición -superaba con creces el millar de piezas- toda vez que parte de ellas se encuentran hoy en paradero desconocido - como casi todas las tablas que nos ocupan- o fueron destruidas en la siguiente Guerra Civil (Navarrete, 2014: 78).

49 Anónimo, 1930: 157-158.

${ }^{50}$ Probablemente se trata de Miguel Sánchez-Dalp y Calonge (1917-1961), primer Conde de Torres de Sánchez-Dalp, insigne personaje de la época que fue Diputado a Cortes, Presidente del Ateneo de Sevilla, etc, miembro, junto con Carlos Pickman entre otros, de la Asociación Sevillana de Arte Antiguo, y destacado coleccionista. (Rodríguez, 2000: 321).

51 Angulo, 1954: 147. 
No obstante, no especifica cuáles eran las que pertenecían todavía a Pickman y cuáles se hallaban en poder de Sánchez-Dalp. A día de hoy, según información facilitada por Carolina Pickman - descendiente del coleccionista-, la Santa Clara, la Natividad y la Lamentación sobre Cristo Muerto se mantienen en propiedad de la familia. Por tanto, la Epifanía sería la obra perteneciente a Sánchez-Dalp. De ser así, desconocemos si sigue en dicha colección o no.

Con mayor generosidad que Gómez Moreno y Angulo a la hora de valorarlas se manifiesta Leandro de Saralegui, quien después de verlas en la Exposición Iberoamericana hace referencia a la Adoración de los reyes y la Natividad en un artículo sobre retablos desmembrados publicado en 1935 en la revista "Museum", de Barcelona. Saralegui, que por su factura y composición dudaba de su origen valenciano, las califica como "bellas" y a su autor como "artista prócer [...] pintor cuatrocentista de gran carácter y excelente maestro, suscitador de dudas y recelos" " 52 , por el problemático origen valenciano de Alonso de Villanueva. Saralegui alude al respecto a dos artistas homónimos, de nombre Sancho y de apellido Villanueva, activos uno en Valencia en 1398 -el mencionado en el catálogo de la Exposición Ibero-Americana- y el otro en Zaragoza entre 1517 y 1541. No obstante, señala:

Pero las fechas imposibilitan el pensar en ninguno de ellos, si no se acaricia la infundada probalidad (sic.) de algún pariente. Tampoco sabemos la procedencia cierta, por más que el muy amable Señor Pickman me indicó los suponía oriundos de la Provincia de Jaén. Quizá Mr. Dupont la sepa con certeza, pues suyas fueron. Andaluzas no las creo. ¿Castellanas o aragonesas? ${ }^{53}$.

Esta afirmación pone nuevamente en contacto a Celestino Dupont con las ventas de patrimonio de las clarisas de Úbeda en la década de 1920. Podría parecer un error, toda vez que el documento de autorización de venta sólo mencionaba a Pickman como comprador. No obstante, Saralegui estaría en lo cierto, pues tenemos constancia de que la Anunciación de Villanueva -no exhibida en la muestra- era propiedad de Dupont en $1922^{54}$, y probablemente lo había sido el resto del conjunto, información que podría conocer de primera mano.

Más difícil de explicar es que Pickman dijese que "suponía que las tablas procedían de la provincia de Jaén", a no ser que en esos pocos años el coleccionista hubiera olvidado su origen, pues el documento del obispado señala claramente que él mismo recogió las tablas en Úbeda y no habría nada que ocultar en un proceso de venta que fue público y transparente. Ello nos lleva a pensar, pese a la anotación del documento, que quizás no fue Pickman quien retiró las tablas, sino Dupont, que habría preferido quedar en el anonimato y que figurase el nombre del coleccionista con quien ya habría apalabrado la compra. Así se explicarían las palabras de Pickman a Saralegui, que quizás supiera por el propio anticuario que las pinturas habían sido suyas o había intermediado en el proceso de compra, quedándose con la Anunciación.

Dejando a un lado las múltiples hipótesis, es evidente que Dupont conocía el monasterio ubetense y su estado de precariedad material. Fue él quien, como hemos visto, compró la Santa Lucía de Williamstown y, quizás también, La Anunciación del MNAC, además de la tabla homónima de Villanueva. Es también obvio que Dupont estaba muy bien relacionado, pues tenía acceso a los cenobios de clausura ${ }^{55}$. No es descabellado pensar, por tanto, en esta intermediación entre Dupont y Pickman.

52 Saralegui, 1935: 372

53 Saralegui, 1935: 372

${ }^{54}$ Así consta en la información que acompaña su reproducción fotográfica en el Arxiu fotografic de Barcelona (AFB, cliché 001233). El Arxiu Mas también conserva fotografías de esta tabla, restaurada y sin restaurar (C-82866 [sin restaurar]; G-51989 [restaurada]), y del resto de piezas del conjunto de Villanueva, a excepción de la Santa Clara: "Adoración de los Santos Reyes" [C-59640]; "Jesús es bajado de la cruz" [C-59661]; "La Natividad" [C-59649].

${ }^{55}$ La doctora Martínez Ruiz señala que precisamente las comunidades de clarisas eran más proclives a la enajenación de su abundante patrimonio mueble que otras órdenes. De igual forma que el favor de la corona y las altas esferas de la 
En cuanto al destino de la Anunciación de Villanueva comprada por Dupont, en los años sesenta pertenecía al anticuario catalán Artur Ramon Garriga, aunque desconocemos su anterior propietario. Podría haberla comprado su padre, Artur Ramon Vendrell, relacionado comercialmente con Dupont, aunque Artur Ramon Picas, tercer miembro de la saga cree que se compró más tarde, cuando su abuelo ya había fallecido. Ramon Garriga la restauró, añadiéndole una crestería medieval, y en los años setenta la vendió al arquitecto Antoni Moragas de Gallissà, conservándose actualmente en la colección familiar.

Con una discreción que no dejó noticia en la prensa local tuvo lugar la venta de la Santa Lucía de Gonçal Peris. Desconocemos por ello en qué momento sucedió, pero sí sabemos, gracias a la mencionada factura, que la tabla fue adquirida por un tal William H. Clarke el 20 de Diciembre de 1924. En los archivos internos del Williams College Museum of Art de Williamstown se conserva un informe elaborado en 1985 por Samson Lane Faison Jr. (1907-2006) ${ }^{56}$, que nos proporciona los detalles y circunstancias de su adquisición.

Según se infiere de este documento, los Clarke eran ávidos coleccionistas que viajaban con frecuencia a Europa en busca de obras de arte ${ }^{57}$. En uno de estos viajes visitaron la residencia de Dupont en Sevilla. Iban acompañados por su hija Lois, a la que años después se consultó para recopilar los datos que originaron el mencionado informe sobre la pieza. De acuerdo a su testimonio, Celestino Dupont vivía en un palacio en Sevilla que enriqueció con su colección de arte $^{58}$ y actuaba como marchante bajo cita previa. Mrs. Clarke localizó la Santa Lucía curiosamente en un baño de la casa, e inmediatamente deseó su adquisición, pagando por ella la mencionada suma de 2500 pesetas, cantidad que coincide con la de las tablas de Villanueva, lo que nos hace pensar que su compra a las clarisas de Úbeda no debió ser muy lejana a la venta del conjunto anterior a Pickman.

Las dificultades económicas derivadas del Crack del 1929 empujaron a los Clarke a deshacerse de alguna obras, escogiendo ésta. El comprador fue Karl E. Weston (1874-1956) ${ }^{59}$, amigo personal de la familia y director del Williams College Museum of Art, que la adquirió para su colección privada. Pagó por ella la misma cantidad que en su día habían desembolsado los Clarke, considerada justa, pues con la crisis los precios habían caído en picado. Pese a que Weston tenía previsto legarla al museo tras su fallecimiento, decidió cederla en vida, aprovechando la inaugu-

nobleza había sido determinante en la creación y crecimiento de este patrimonio, estos mismos vínculos explicarían en parte su mayor contacto con exterior y las facilidades para su venta. (Martínez Ruiz, 2015: 171-200).

${ }^{56}$ Historiador del Arte, discípulo de Karl E. Weston, Marcel Aubert y Henry Focillon, fue profesor y director del Williams College Museum of Art desde 1948 hasta 1976. Formó parte, a su vez, del equipo de los Monuments men que investigó el robo de arte por parte de los nazis. Cuando redactó el informe de esta tabla era director emérito del Museo. Para más información acerca de este personaje vid. SORENSEN, L. "S. Lane Faison". En: Dictionary of Art historians $<\mathrm{http} / / /$ www.dictionaryofarthistorians.org/faisons.htm $>$ [21/12/2014].

${ }^{57}$ No hemos podido encontrar apenas información sobre estos personajes. Al parecer eran de Stockbridge (Massachusets) y vivían en una villa que evocaba las de la Toscana, conocida como "Villa Virginia", y que donaron varias piezas de su colección al Museo.

${ }^{58}$ Era en realidad una casa de estilo sevillano situada en la calle Albareda 34, y debía de ser esplendorosa y estar ricamente decorada -ya que a Mrs. Clarke le pareció un palacio-, al igual que la que fue su residencia en Barcelona, la Villa Hispanoárabe, que no vendió hasta 1934 (Véase: Beltrán, 2014:79-112; 2015, 27-50).

${ }^{59}$ Historiador del arte, fundó en 1926 el Williams College Museum of Art, que por aquel entonces se llamaba The Lawrence Art Museum, del que fue profesor y primer director hasta que se retiró en 1948. Weston ayudó a convencer a Robert Sterling Clark (1877-1956), heredero de la fortuna de la Singer Corporation y gran coleccionista de arte, para ubicar el Sterling and Francine Clark Art Institute adyacente al campus del Williams College, en 1950. La factura original fue conservada por el señor Weston, que la entregó al museo en el momento de donar la tabla, lo que nos ha permitido conocer que fue Dupont el responsable de su salida al extranjero. Para más información sobre este personaje vid. Sorensen,L. "Karl E. Weston". Dictionary of Art historians http://www.dictionaryofarthistorians.org/westonk.htm [21/12/2014]. 
ración de la sala Cluett, dedicada al arte español y formada a partir de una importante donación del coleccionista George Alfred Cluett (1873-1955).

\section{Conclusión}

Las vicisitudes experimentadas por estos "primitivos" del Real Monasterio de Santa Clara de Úbeda tienen un triple interés. Por un lado, aportan verosimilitud a la hipotética y, en principio, dudosa existencia de pintura valenciana bajomedieval en el Alto Guadalquivir, revelando que antes de la gran eclosión artística del Renacimiento y, a pesar de la ausencia de grandes maestros y de las inquietudes y peligros derivados de su situación fronteriza con el reino nazarí de Granada, existía una actividad creativa de interés en la zona, aun habiendo de recurrir a artistas foráneos. Permiten afirmar también que los intercambios artísticos entre los reinos cristianos peninsulares no fueron extraños y no sólo contaron con los obradores y centros creativos más cercanos. Finalmente ilustran que a pesar del incipiente interés por el patrimonio demostrado por las élites intelectuales de la provincia de Jaén en las primeras décadas del siglo XX, los bienes culturales de Úbeda estaban en almoneda; los casos de estos "primitivos", de la portada de los Aranda, o de la emblemática Casa de las Torres - en el objetivo de Arthur Byne, uno de los agentes del conocido magnate William Randolph Hearst, aunque afortunadamente la compra no llegó a producirse ${ }^{60}$ son ejemplos locales a la vez que muy significativos de la dispersión del patrimonio histórico español acontecida en estas décadas.

\section{BIBLIOGRAFÍA}

Alcoy Pedrós, Rosa (1992): "El retaule de Santa Bàrbara de Puertomingalvo". En: Prefiguració del Museu d'Art de Catalunya. Barcelona: Museu Nacional d'Art de Catalunya, pp. 260-263

Almagro García, Antonio (1989): Santa María de los Reales Alcázares de Úbeda. Úbeda, Asociación "Pablo de Olavide" para defensa del Patrimonio Cultural Andaluz.

Angulo Íñiguez, Diego (1944): "Pintores cordobeses del Renacimiento". En: Archivo Español de Arte, núm. 17, Madrid: CSIC, pp. 227-236.

Angulo Íñiguez, Diego (1954): Pintura del Renacimiento. En: Ars Hispaniae. Historia Universal del Arte Hispánico. Madrid: Plus Ultra.

Anónimo (1921): “Los primitivos del Convento de Santa Clara, de Úbeda. En: Don Lope de Sosa, núm. 101, Jaén, p. 130.

Anónimo (1930): Exposición Ibero-Americana. Catálogo del Palacio de Bellas Artes. Sección de Arte Antiguo. Sevilla, Imprenta de la Exposición.

Beltrán Catalán, Clara (2014): Celestino Dupont (1859-1940) y el comercio de antigüedades en Cataluña: de la esfera privada al ámbito internacional. Tesis de Máster. Barcelona: Universidad de Barcelona, 2014. Disponible en línea: http://hdl.handle.net/2445/60136.

Beltrán Catalán, Clara (2015): "La Villa Hispanoárabe: Oriente en el Tibidabo". En: Res Mobilis. Revista internacional de investigación en mobiliario y objetos decorativos, núm. 4, Oviedo, pp. 27-50.

Beltrán Catalán, Clara (2016): "L’antiquari Celestí Dupont (1895-1940). Colleccionisme i comerç d'art a la Catalunya d'entre segles". En: Colleccionistes, antiquaris, falsidicadors i museus. Novesdades sobre el patrimoni artistic de Catalunya al segle XX, en prensa.

Berenguer, Mireia (2010): "La incidència de la venda de la col·lecció Plandiura a la premsa de l'època". En: Butlletí de la Reial Acadèmia Catalana de Belles Arts de Sant Jordi, vol. XVI, núm. 2, Barcelona, pp. 11-25.

Berenguer, Mireia (2002): "Lluís Plandiura una vida entregada a l'art". En: Revista de Catalunya, núm. 171, Barcelona, pp. 23-40.

\footnotetext{
${ }^{60}$ Merino de Cáceres / Martínez Ruiz, 2012: 374-384.
} 
Berg Sobre, Judith/Travers Newton, Henry (1998): "Saint Lucy attributed to Gonçal Peris and workshop practices in the Early Fifteenth Century Crown of Aragon". En: Miscel-lània en homenatge a Joan Ainaud de Lasarte. Barcelona: Museu Nacional d'Art de Catalunya, Institut d'Estudis Catalans, Publicacions de 1'Abadia de Montserrat, pp. 407-416.

Borobia, Mar (2011): "La Virgen con el Niño, c. 1470, atribuido a Andrea del Verrochio" (ficha de catálogo). En: Arquitecturas pintadas. Del Renacimiento al siglo XVIII (catálogo de exposición). Madrid: Museo Thyssen Bornemisza, Fundación Caja Madrid.

Cornudella, Rafael (2009): "Retablo de Santa Bárbara". En: La Edad de oro del arte valenciano: rememoración de un centenario Museo de Bellas Artes de Valencia. Valencia: Generalitat Valenciana, pp. 134-139.

Gómez Moreno, Manuel (1921): “Tablas del Convento de Santa Clara de Úbeda”. En: Don Lope de Sosa, núm. 99, Jaén, pp. 67-71.

Gudiol, José (1955): Pintura gótica. En: Ars Hispaniae. Historia Universal del Arte Hispánico, vol. IX, Madrid: Plus Ultra.

Laín y Roxas, Salvador (2012): Historia de la Provincia de Granada de los Frailes Menores de N.P.S. Francisco (1819). Martos: Fundación Cultural y Misión San Francisco de Asís.

Mâle, Èmile (2001): El arte religioso del siglo XIII en Francia. Madrid: Encuentro.

Martínez-Ruíz, María José: "Depredadores de conventos. Comercio de antigüedades en el entorno de las clausuras españolas: Lionel Harris”. En: Alsina, Esther/Beltrán, Clara (eds.), El reverso de la Historia del Arte. Exposiciones, comercio y coleccionismo (1850-1950)". Gijón: Trea, pp. 171-200.

Merino de Cáceres, José Miguel/Martínez-Ruiz, María José (2012): La destrucción del patrimonio artístico español. W. R. Hearst: "el gran acaparador". Madrid: Cátedra.

Moreno Mendoza, Arsenio (2002): "La pintura en Úbeda en el siglo XVI”. En: Laboratorio de Arte, núm. 15, Sevilla, pp. 83-109.

Navarrete, Benito (2014): "Francisco Murillo Herrera y Diego Angulo en la Exposición de Arte Antiguo de 1929: una actuación clave para el Laboratorio de Arte de la Universidad de Sevilla". En: Navarrete Benito (ed. y coord.): Arte Antiguo en la Exposición Iberoamericana de 1929. Sevilla: Instituto de la Cultura y de las Artes de Sevilla, pp. 66-99.

Pareja, Enrique/Megía, Matilde (1990): El arte de la Reconquista cristiana. En: Historia del Arte en Andalucía. Sevilla: Gever.

Post, Chandler (1935): A History of Spanish Painting: The Valencian School in the Late Middle Ages and Early Renaissance, Vol. VI. Cambridge, Massachusets: Harvard University Press.

Réau, Louis (1996): Iconografia del arte cristiano. Barcelona: Serbal.

Rodríguez, Immaculada (2000): Arte y cultura en la prensa: la pintura sevillana (1900-1936). Sevilla: Universidad de Sevilla. Secretariado de Publicaciones.

Romero de Torres, Enrique (1913): Catálogo de los Monumentos Históricos y Artísticos de la Provincia de Jaén. Formado en virtud de R.O. de 30 de enero de 1913 (Manuscrito).

Ruiz, Francesc (2012): "Del obispo Sapera a los linajes Pomar y Nadal. Gonçal Peris y los retablos de Puertomingalvo". En: Retrotabulum, núm. 5, pp.11-36.

Ruiz Prieto, Miguel (1906): Historia de Úbeda. Úbeda: Asociación Cultural Pablo de Olavide (Edición digital de 2006, conmemorativa del centenario de su publicación).

Saralegui, Leandro (1935): "Restos de retablos descabalados". En: Museum: revista mensual de arte español antiguo y moderno y de la vida artística contemporánea, Vol. VII, núm. 10, Barcelona, pp. 353-372.

Tarifa, Adela/Linage, José Antonio (1994): "Crónica de un convento de clausura en Úbeda durante la Guerra Civil: la comunidad de Santa Clara de 1936 a 1942”. En: Boletín del Instituto de Estudios Giennenses (153, 2). Jaén: Diputación Provincial de Jaén, pp. 1071-1096.

Torres Navarrete, Ginés (1990): Historia de Úbeda en sus documentos. Conventos (III). Úbeda: Minerva.

Thode, Henry (1993): Francesco d'Assisi e le origini dell'arte del Rinascimento in Italia. Roma: Donzelli.

Fecha de recepción: 02-III-2015

Fecha de aceptación: 10-VII-2015 